\title{
Suicide in Neurological Disorders
}

\author{
Raymond A. Faber \\ University of Texas Health Science Center at San Antonio, San Antonio, Tex., USA
}

Suicide is an avoidable tragedy. The clinicians' interest and vigilance are the most potent available deterrents. Individuals in high-risk groups can be identified, and practical, effective interventions are available. A number of neurological disorders have been identified among risk factors for suicide, so it behooves neurologists to be mindful of these conditions and to have a general awareness of suicide potential and management options. In the accompanying article, Fredrikson et al. [1] confirm an elevated risk of suicide in patients with multiple sclerosis. The twofold increase in standardized mortality ratio was comparable with that found in an earlier Danish study [2]. The methods by Fredrikson et al. [1] were excellent, yet in interpreting their work, it must be remembered that their lengthy data collection period was mainly in a period of relative therapeutic nihilism, before $\beta$-interferon became available. Now that effective treatments for multiple sclerosis are available, the hopelessness of sufferers may be mitigated. The highest risk of suicide was amongst younger males in the early years after diagnosis. Male gender is a very well recognized risk factor for suicide, partially because of its association with alcohol abuse.

Other neurological disorders also confer an increased risk of suicide [3]. Stroke increases suicide risk [4]. Poststroke depression is often the soil from which suicide ideation emerges. The presence of persistent physical and cognitive impairments also contributes to suicide risk. Particular mention needs to be made of right frontal lobe strokes, which cause a motor aprosodia. In such instances, though these patients may complain of significant dysphoria, hopelessness, and suicide ideation, their inability to convey emotionality and feeling can cause disbelief in observers who tend to underestimate the severity of such utterances [5].

Huntington's disease carries an increased risk of suicide. In his original article, Huntington [6] stated 'the tendency to insanity and sometimes to that form of insanity which leads to suicide is marked'. Huntington patients are at risk for a plethora of psychiatric disturbances including mood disorders, psychosis, and personality disorders [7]. Even asymptomatic individuals at risk for Huntington's disease need to be carefully screened for suicide ideation, before and after predictive genetic testing is carried out [8].

Epilepsy also carries an increased risk of suicide [9]. In addition to comorbid psychopathology, other factors increasing risk include higher seizure frequency and the need for multiple antiepileptic medications [10]. Temporal lobe foci may be a risk factor, but it may be their association with psychopathology that leads to suicide risk. Occasionally effective treatment results in the phenomenon of forced normalization wherein seizures are controlled but mental status deteriorates, sometimes dramatically so [11]. Vigabatrin has been associated with depression, but most newer antiepileptic drugs are either psychiatrically benign or even beneficial, i.e. divalproex and

\section{KARGER \\ Fax +41613061234 \\ E-Mail karger@karger.ch \\ www.karger.com

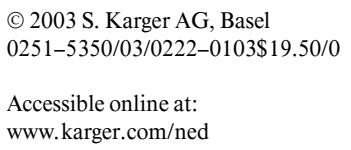

Prof. Raymond A. Faber

University of Texas Health Science Center

7703 Floyd Curl Drive

San Antonio, TX 78229-3900 (USA)

E-Mail faberr@uthscsa.edu 
lamotrigine [12]. Migraine with aura even without coexisting depression is reportedly a risk factor for suicide, which bears mentioning [13].

There is probably an increased risk of suicide in the early stages of dementias. The incidence of depression is clearly increased in this population and one autopsy study found an increase in Alzheimer's pathology in suicide completers. Clearly as dementias progress and individuals lose executive functions, the risk of suicide declines along with the incidence of depression. Traumatic brain injury of all severities increases suicide risk [14]. Because of the often profound physical, psychological, and social consequences of traumatic brain injury, this population needs close assessment for suicide ideation. It appears that Parkinson's disease is associated with a decreased risk of suicide in spite of an increased rate of depressive symptoms in Parkinson's disease [15]. Motor and psychic slowing along with executive dysfunction are presumed explanations.

\section{Assessment and Management}

The single most important predictor of suicide is the presence of depression. All patients should be screened for depression. If patients deny being depressed, having a decreased interest in usual pursuits, or deriving less pleasure from usually pleasurable activities, there is no need for further inquiry. However, if any of these three probes are answered in the affirmative, it is essential to assess for the presence of major depression. The well-known acronym 'SIG E CAPS + mood' is a convenient aid in reviewing relevant symptoms. 'SIG E CAPS' stands for sleep (insomnia or hypersomnia), interests (diminished), guilt, energy, concentration, appetite, psychomotor (retardation or agitation), and suicide ideation. Major depression is diagnosed if there are disturbances of five or more symptoms for at least 2 weeks. In depressed patients, the degree of hopelessness correlates more strongly with suicide potential than severity of depression or sadness. In directly assessing suicide potential, it is best to start with inquiries by asking: 'Do you ever feel life is not worth living?' If the answer is yes, one should follow with a graded series of questions concerning the determination to act on such feelings and if the patient has developed a specific suicide plan. If so, the patient should be asked for a specific time frame they are willing to live before acting on their plan. Often patients will agree to wait and see how stressful circumstances in their life evolve. They may also agree to keeping a follow-up appointment or accepting referral to a psychiatrist in the near future. If they cannot make such a commitment, the clinician must take decisive action including the possibility of involuntary commitment to a facility to prevent an imminent suicide attempt. It is important to realize that making the above inquiries does not give patients the impetus to attempt suicide. The opposite is true. Getting patients to talk about any suicide ideation usually defuses the intensity of such ideas.

Treatments for depression are effective. Medications are more practical than psychotherapies but some patients will rather talk if such therapy is available. The most popular antidepressants are the serotonin-specific reuptake inhibitors. Though they are no more effective than the displaced tricyclic antidepressants, they are better tolerated and have negligible toxicity in overdose attempts. There is accumulating data that since their widespread acceptance, rates of suicide have declined. All clinicians should be comfortable initiating antidepressant treatment. For refractory depressions, psychiatrists tend to combine medications with differing mechanisms of action. Finally though, more labor-intensive and thus more costly, electroconvulsive therapy is unsurpassed in efficacy for treating severe depression. In Parkinson's disease, electroconvulsive therapy can improve motor symptoms as well as treat depression [16].

Attending to depression and suicidality are vital components of treating our patients as unique and valued human beings. Such humanistic concerns must always remain a medical priority, even as technology allows us to perform virtual miracles. 


\section{References}

1 Fredrikson S, Cheng Q, Jiang G-X, Wasserman D: Elevated suicide risk among patients with multiple sclerosis in Sweden. Neuroepidemiology 2003;22:146-152.

2 Stenager EN, Stenager E, Koch-Henriksen N, Broonum-Hansen H, Hyllested K, Jensen K, Bille-Brahe U: Suicide and multiple sclerosis: An epidemiological investigation. J Neurol Neurosurg Psychiatry 1992;55:542-545.

3 Arciniegas DB, Anderson CA: Suicide in neurologic illness. Curr Treat Options Neurol 2002;4:457-468.

4 Stenager EN, Madsen C, Stenager E, Boldsen J: Suicide in patients with stroke: Epidemiological study. BMJ 1998;316:1206.

5 Ross ED, Mesulam M-M: Dominant language functions of the right hemisphere: Prosody and emotional gesturing. Arch Neurol 1979;36. 144-148.
6 Huntington G: On chorea. Med Surg Rep 1872; 26:317-321.

7 Naarding P, Kremer HPH, Zitman FG: Huntington's disease: A review of the literature on prevalence and treatment of neuropsychiatric phenomena. Eur Psychiatry 2001;16:439-445.

8 Almqvist EW, Bloch M, Brinkman R, Craufurd D, Hayden MP: A worldwide assessment of the frequency of suicide, suicide attempts, or psychiatric hospitalization after predictive testing for Huntington's disease. Am J Hum Genet 1999;64:1293-1304.

9 Barraclough BM: The suicide rate of epilepsy. Acta Psychiatr Scand 1987;76:339-345.

10 Mendez MF, Doss RC: Ictal and psychiatric aspects of suicide in epileptic patients. Int $\mathbf{J}$ Psychiatry Med 1992;22:231-237.
11 Krishnamoorthy ES, Trimble MR: Forced normalization: Clinical and therapeutic relevance. Epilepsia 1999;40(suppl 10):S57-S64.

12 Schmitz B: Psychiatric syndromes related to antiepileptic drugs. Epilepsia 1999;40(suppl 10):S65-S70.

13 Breslau N: Migraine, suicidal ideation, and suicide attempts. Neurology 1992;42:392-395.

14 Teasdale TW, Engberg AW: Suicide after traumatic brain injury: A population study. J Neurol Neurosurg Psychiatry 2001;71:436-440.

15 Myslobodsky M, Lalonde FM, Hicks L: Are patients with Parkinson's disease suicidal? Geriatr Psychiatry Neurol 2001;14:120-124.

16 Faber R, Trimble MR: Electroconvulsive therapy in Parkinson's disease and other movement disorders. Mov Disord 1991;6:293-303. 